\title{
OPTIMIZATION OF THE BIOEQUIVALENCE STUDY OF ESOMEPRAZOLE CAPSULE CONTENTS AFTER IN VITRO SUSPENSION IN SOFT FOODS USING HPLC
}

\author{
${ }^{1}$ M. Alauddin, ${ }^{2}$ K. M. Z. Hossain, ${ }^{2}$ M. A. Rahman, ${ }^{3}$ A. S. M. H. Kabir and ${ }^{4}$ I. H. Khan \\ ${ }^{1}$ Department of Biochemistry and Molecular Biology, University of Dhaka \\ ${ }^{2}$ Faculty of Science and Information Technology, Daffodil International University, Dhaka \\ ${ }^{3}$ Department of Applied Chemistry and Chemical Technology, University of Dhaka \\ ${ }^{4}$ Department of Microbiology, University of Dhaka \\ E-mail: arif_pr@daffodilvarsity.edu.bd
}

\begin{abstract}
A bioequivalence study for the selection of the alternative and feasible mode of administration of esomeprazole pellets suspended in some common soft liquid foods has been done. $20 \mathrm{mg}$ of four different brands esomeprazole pellets suspended in yogurt, orange juice, apple juice and milk were analyzed in the gastric environment using dissolution tester and high performance liquid chromatography. The release of the esomeprazole active was found more the 90\% using these liquid foods except milk. The optimal release of the active was found in the system of apple juice (97.06\%). Administration of the esomeprazole pellets suspending in apple juice may be a practical alternative for patients who cannot swallow an intact capsule.
\end{abstract}

Keywords: Bioequivalence, Esomeprazole pellets, Soft foods, Gastric environment, Dissolution.

\section{Introduction}

Esomeprazole magnesium, content of delayed release capsules is bis(5-methoxy-2[(S)-[(4-methoxy-3,5-dimethyl-2-

pyridinyl)methyl] sulfinyl]-1Hbenzimidazole-1-yl)magnesium trihydrate, a compound that is widely used as a proton pump inhibitor for the treatment of various acid-related disorders. Esomeprazole is the Sisomer of omeprazole, which is a mixture of the $\mathrm{S}$ - and $\mathrm{R}$ - isomers. Its empirical formula is $\left(\mathrm{C}_{17} \mathrm{H}_{18} \mathrm{~N}_{3} \mathrm{O}_{3} \mathrm{~S}\right)_{2} \mathrm{Mg} .3 \mathrm{H}_{2} \mathrm{O}$ with molecular weight of 767.2 as a trihydrate and 713.1 on an anhydrous basis. The structural formula is: Esomeprazole is currently supplied in Bangladesh as $20 \mathrm{mg}$ or $40 \mathrm{mg}$ capsule<smiles></smiles>

containing pellets. Many patients in Bangladesh have difficulty in swallowing capsules containing enteric coated pellets of esomeprazole because of general abrasion, hyperactive gag reflex, or dysphagia [1-3]. However, there are situations in which gastric acid suppression is necessary for patients who are unable to take medication by mouth [4]. For such patients modes of administration other than an intact capsule are desirable. Extemporaneously compounded liquid formulations such as sodium bicarbonate suspension or solutions combined with different proton pump inhibitors have been used [5]. About 98 99\% delivery of esomeprazole magnesium pellets was observed in vitro when the pellets were dispersed in tap water [6]. Stability of esomeprazole capsule contents in different common soft liquid foods and water were also studied [7].

The objective of the study was to determine the optimal medium for the delivery of esomeprazole magnesium enteric coated pellets suspended in different soft liquid foods.

\section{Experimental}

\subsection{Collection and Preparation of Media} and Sample

Apple juice (Cyprina), orange juice (ACME), yogurt (Aarong) and milk (Milk Vita -1.5\% fat) were collected locally. $\mathrm{HCl}$ (0.1M) solution was prepared from $37 \% \mathrm{HCl}$ (Merck, Germany). Four different brands of esomeprazole capsules such as, Nexium (AstraZeneca, Sweden), Sergel (Healthcare Pharm. Ltd), Neptor (Novartis Bangladesh 
Ltd.), Maxpro (Renata Ltd.) were collected and analyzed.

Single esomeprazole 20-mg capsule contents were weighed and emptied into individual USP vessels of dissolution tester (Erweka, Germany) containing $100 \mathrm{~mL}$ of liquid soft foods. After 30 minutes, $500 \mathrm{~mL}$ of hydrochloric acid $(0.1 \mathrm{M})$ was added to each vessel. After 2 hours dissolution $\mathrm{pH}$ values were measured using hand $\mathrm{pH}$ meter (Hanna HI98127, USA), and the pellets were collected and transferred into a 250-mL volumetric flask containing approximately $100-\mathrm{mL}$ water. $50 \mathrm{~mL}$ phosphate buffer solution (pH 11.0 phosphate buffer- $965.3 \mathrm{ml}$ of $0.1 \mathrm{M}$ disodium hydrogen phosphate solution was mixed with $34.7 \mathrm{ml}$ of $0.1 \mathrm{M}$ sodium hydroxide, to obtain $1000 \mathrm{~mL}$. The $\mathrm{pH}$ was adjust to $11.0 \pm 0.05$ with phosphoric acid or sodium hydroxide) was added and the mixture was agitated in the mechanical shaker machine for 20 minutes. After another 5 minutes in an ultrasonic bath at ambient temperature the flask was shaken by hand and $50 \mathrm{~mL}$ of $95 \%$ ethanol was added. Next the flask was shaken by hand again, and the contents were filtered through $0.45 \mu$ filter paper. The filtrate was diluted to 5 times with water [7].

\subsection{Standard Preparation}

About $20 \mathrm{mg}$ of esomeprazole working standard was weighed and was transferred to a $50 \mathrm{ml}$ volumetric flask. Methanol $(40 \mathrm{ml})$ was added and was sonicated to dissolve. It was made volume up to the mark with
Methanol. $10 \mathrm{ml}$ of this solution was diluted to $50 \mathrm{ml}$ with the dissolution media.

\subsection{Preparation of mobile phase}

Mobile phase was prepared by mixing with $350 \mathrm{~mL}$ acetonitrile \& $500 \mathrm{~mL}$ phosphate buffer (pH 7.3). This mixture was diluted to $1000 \mathrm{~mL}$ with distilled water. Phosphate buffer - $\mathrm{pH} 7.3$ was prepared by dissolving $6.8 \mathrm{gm}$ of monobasic potassium phosphate in water to obtain $250 \mathrm{ml}$ of solution. $250 \mathrm{ml}$ of this solution was mixed with $36.9 \mathrm{ml}$ of $0.2 \mathrm{M}$ $\mathrm{NaOH}$ and was volume with distilled water up to $1000 \mathrm{~mL}$. The $\mathrm{pH}$ was adjusted to $7.3 \pm$ 0.05 with phosphoric acid or potassium hydroxide. The mixture was filtered, degassed and used as mobile phase.

\subsection{Chromatographic Condition}

High Performance Liquid Chromatography (HPLC- Shimadzu Prominence, Japan) with $1.0 \mathrm{~mL} / \mathrm{min}$ flow rate, $20 \mu \mathrm{l}$ loop injector, ambient column oven temperature and detection wavelength $302 \mathrm{~nm}$ (PDA detector) was used for this analysis. Hypersil $0.250 \mathrm{~m}$ long and $4.6 \mathrm{~mm}$ internal diameter column, packed with octadecylsilyl silica gel $(5 \mu \mathrm{m})$ was used for chromatographic analysis.

\section{Results and Discussion}

The suspensions of esomeprazole enteric coated pellets from four different brands products in yogurt, orange juice, apple juice and milk were analyzed.

The $\mathrm{pH}$ of esomeprazole enteric coated pellets suspended in yogurt, apple juice, orange juice and milk were determined, which is shown in the Table 1.

Table 1 Mean pH of esomeprazole pellets in common liquid foods to an acidic environment.

\begin{tabular}{|c|c|c|c|}
\hline Liquid Foods & $\begin{array}{c}\text { Initial } \\
\text { pH of } \\
\text { Liquid Foods }\end{array}$ & $\begin{array}{c}\mathrm{pH} \text { of the Suspension in } \\
\text { Liquid Foods and 500ml } \\
0.1 \mathrm{M} \mathrm{HCl}\end{array}$ & $\begin{array}{c}\text { Mean } \mathrm{pH} \\
\pm \\
\text { Standard Deviation }\end{array}$ \\
\hline Yogurt & 3.76 & $1.41,1.40,1.35,1.39$ & $1.38 \pm 0.03$ \\
\hline Orange juice & 3.80 & $1.31,1.37,1.32,1.40$ & $1.35 \pm 0.04$ \\
\hline Apple juice & 3.16 & $1.33,1.34,1.28,1.37$ & $1.33 \pm 0.04$ \\
\hline Milk & 6.82 & $3.45,3.41,3.39,3.43$ & $3.42 \pm 0.03$ \\
\hline
\end{tabular}

The initial $\mathrm{pH}$ of the different types of soft foods was found quite acidic and almost similar except for system of milk. The $\mathrm{pH}$ of milk was found close to neutral (6.82). With the addition of hydrochloric acid $(0.1 \mathrm{M} \mathrm{HCl})$ to the suspension and subsequent dissolution, the $\mathrm{pH}$ of the suspension dropped significantly in all systems. 
The potency of different brands esomeprazole capsule contents were evaluated using reverse phase HPLC and the results obtained are shown in the Table 2 . The initial potency were found 99.42 $101.50 \%$ for the four different brands esomeprazole capsule content.

Table 2 Initial potency of different brand esomeprazole capsule.

\begin{tabular}{|c|c|c|}
\hline $\begin{array}{c}\text { Esomeprazole } \\
\text { Sample }\end{array}$ & $\begin{array}{c}\text { Specification } \\
\text { (\%) }\end{array}$ & $\begin{array}{c}\text { Initial } \\
\text { Potency } \\
\text { (\%) }\end{array}$ \\
\cline { 1 - 1 } Sample-A & & 99.45 \\
\cline { 1 - 1 } Sample-B & \multirow{2}{*}{$90.00 \sim$} & 101.50 \\
\cline { 1 - 1 } \cline { 1 - 1 } Sample-C & 110.00 & 99.92 \\
\hline Sample-D & & 101.17 \\
\hline
\end{tabular}

Table 3 shows the percent stability of esomeprazole pellets in common liquid foods. The bioequivalence of esomeprazole enteric-coated pellets was not affected by suspension in any of the soft foods tested, except milk. The decreased bioequivalence of the esomeprazole pellets in milk, which has a high buffering capacity, may have been due in part to its near-neutral $\mathrm{pH}$, which caused dissolution of the enteric-coated polymer of the pellet, with release of its contents and rapid degradation after acid exposure.

Table 3 The stability of esomeprazole pellets in common liquid foods by HPLC method

\begin{tabular}{|c|c|c|}
\hline $\begin{array}{c}\text { Liquid } \\
\text { Foods }\end{array}$ & $\begin{array}{c}\text { Stability of } \\
\text { esomeprazole } \\
\text { pellets } \\
(\%)\end{array}$ & $\begin{array}{c}\text { Mean Stability } \\
(\%) \pm \\
\text { Standard } \\
\text { Deviation }\end{array}$ \\
\hline Yogurt & $\begin{array}{c}99.26,91.90, \\
92.55,91.63\end{array}$ & $93.83 \pm 3.6$ \\
\hline $\begin{array}{c}\text { Orange } \\
\text { juice }\end{array}$ & $\begin{array}{c}98.28,92.05, \\
95.20,98.25\end{array}$ & $95.94 \pm 2.9$ \\
\hline Apple juice & $\begin{array}{c}98.86,96.90, \\
94.15,98.33\end{array}$ & $97.06 \pm 2.1$ \\
\hline Milk & $\begin{array}{c}58.15,49.21, \\
53.60,51.63\end{array}$ & $53.14 \pm 3.7$ \\
\hline
\end{tabular}

After addition of the esomeprazole pellets to an alkaline medium, more than $90 \%$ of the esomeprazole was recovered from all the soft liquid foods except the system containing milk(only $49 \sim 58 \%$ recovered). The percent stability of esomeprazole magnesium suspended in yogurt, orange juice and apple juice were found $93.83( \pm 3.6), 95.94( \pm 2.9)$ and $97.06( \pm 2.1)$ respectively in gastric environment, which is good.

\section{Conclusion}

Administration of esomeprazole enteric coated pellets suspended in yogurt, orange juice and apple juice were found in vitro delivered over $90 \%$ of the active. The optimum release of the esomeprazole active was found for the system of apple juice, which is about $97.06 \%$. So, those patients [8] who have pain or difficulty with swallowing intact capsule can take the capsule contents suspended in apple juice for feasible and also comfortable administration of medication.

\section{Acknowledgement}

Thanks are due to Reneta Limited, Mirpur Plant, Dhaka, Bangladesh for their cordial help and cooperation.

\section{References}

[1] N. B. Vakil, S. Zuckerman, and J. G. Levine, "Dysphagia in uncomplicated reflux disease", Gastroenterology, Vol.122, 2002, A583.

[2] P. J. Kahrilas, G. W. Falk, and D. A. Johnson, "Esomeprazole improves healing and symptom resolution as compared with omeprazole in reflux oesophagitis patients: a randomized controlled trial. The Esomeprazole Study Investigators", Aliment Pharmacol Ther, Vol. 14, 2000, pp. 12491258.

[3] J. E. Richter, P. J. Kahrilas, and J. Johanson, "Efficacy and safety of esomeprazole compared with omeprazole in GERD patients with erosive esophagitis: a randomized controlled trial”, $A m J$. Gastroenterol, Vol. 96, 2001, pp. 656-665.

[4] M. C. Bechwith, S. S. Feddema, and R. G. Barton, "A guide to drug therapy in patients with eternal feeding tubes: dosage form selection and administration methods", Hosp. Pharm, Vol. 39, 2004, pp. 225-237.

[5] L. S. Welage, "Overview of pharmacological agents for acid suppression in critically ill patients”, Am. J. Health-Syst Pharm, Vol. 62 (2), 2005, S4-10.

[6] C. M. White, J. Kalus, and R. Quercia, "Delivery of esomeprazole magnesium enteric coated pellets through small caliber and standard nongastric tubes and gastronomy tubes in vitro", Am. J. Health-Syst Pharm, Vol. 59, 2002, 2085-2088.

[7] D. A. Johnson, A. C. Roach, A. S. Carlsson, A. A. S. Karlsson and D. E. Behr, "Stability of esomeprazole capsule contents after in vitro suspension in common soft foods and beverages", Pharmacotherapy, Vol. 23 (6), 2003, pp. 731-734.

[8] S. R. Barczi, P. A. Sullivan, and J. Robbins, "How should dysphagia care of older adults differ? Establishing optimal practice patterns", Semin Speech Lang, Vol. 21, 2000, pp. 347-349. 